\title{
Pioneirismo, inovações, crises financeiras e a transição de plataforma na história do Jornal do Brasil
}

\section{Pioneros, innovación, crisis financiera y cambio de plataforma en la historia del periódico de Brasil}

\section{Fernanda Vasques Ferreira (Brasil) Universidade Católica de Brasilia (UCB) Doutoranda no Programa de Pós-Graduação da Faculdade de Comunicação da Univer- sidade de Brasília (UnB), professora da Universidade Católica de Braślia (UCB) jornalista82@gmail.com}

\author{
Flávia Simone Pereira De Sousa (Brasil) \\ Graduada em Comunicação Social - Jornalismo, \\ trabalha na área de assessoria de comunicação \\ vinha.jornalismo@gmail.com
}

\begin{abstract}
Resumo
A concorrência com o jornal $\bigcirc$ Globo, o avanço tecnológico, a má administração e os altos custos para manter sua versão impressa, o Jornal do Brasil anunciou em 2010 o fim da utilização do papel para divulgação de notícias, que passaram a ser disponibilizadas somente na internet.
\end{abstract}

\begin{abstract}
The competition with the newspaper $O$ Globo, technological advancement, mismanagement and high costs to maintain its printed version, Journal of Brazil announced in 2010 the end of the use of paper to distribute news that became available only on the Internet. The paper
\end{abstract}

$\begin{array}{lr}\text { FECHA DE RECEPCIÓN: } & 20 \text { de marzo de } 2014 \\ \text { FECHA DE REVISIÓN: } & 25 \text { de junio de 2014 } \\ \text { APROBACIÓN: } & 29 \text { de junio de } 2014\end{array}$

FECHA DE RECEPCIÓN: FECHA DE REVISIÓN: 25 de junio de 2014

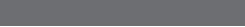


O trabalho analisa os elementos que ocasionaram o fim da versão impressa do Jornal do Brasil e levaram um dos maiores jornais do país a manter seu conteúdo somente na plataforma digital. Adotou-se o estudo de caso do jornal. A pesquisa destaca a história do jornal que publicou capas inesquecíveis e polêmicas. São apontadas suas inovações, que influenciaram toda a imprensa brasileira.

Palauras-chave: jornal do Brasil, história do jornalismo, jornalismo digital, crise financeira. analyzes the factors that led to the end of the printed version of the Journal of Brazil and led one of the biggest newspapers in the country to keep its content only on the digital platform. We use the case study of the newspaper. The research highlights the history of the newspaper that published controversial and memorable covers. Their innovations, which influenced the whole brazilian press are pointed.

Keywords: Journal of Brazil, history of journalism, digital journalism, financial crisis.

\section{Resumen}

En 2010, debido a la competencia con el periódico O Globo, a los avances tecnológicos, a una mala administración y a los altos costos de tener una versión impresa, el Periódico de Brasil [Jornal do Brasil en portugués] anunció el fin del uso de papel para publicar las noticias, que iban a estar disponibles solamente a través del Internet. Este artículo analiza los factores que condujeron al fin de la versión impresa del Periódico de Brasil, llevando así a uno de los periódicos más grandes del país a mantenerse solamente en versión digital. La investigación usa como caso de estudio al periódico, resaltando su historia y reputación como el periódico que publicó portadas controversiales y memorables, que fueron innovadoras e influenciaron la prensa brasileña.

Keywords: Periódico de Brasil, historia del periodismo, periodismo digital, crisis financiera. 


\section{Pioneirismo, inovações, crises financeiras e a transição de plataforma na história do Jornal do Brasil}

\section{Pioneros, innovación, crisis financiera y cambio de plataforma en la historia del periódico de Brasil}

\section{Fernanda Vasques Ferreira (Brasil)}

Pertence à linha de investigação Jornalismo

e Sociedade, estuda teoria do agendamento, telejornalismo e cidadania, internaccão compulsória de usuários de crack. É professora há dez em curso superior de jornalismo e publicidade, já deu aula em curso de pós-graduação lato sensu, trabalhou em assessoria de imprensa na Câmara dos Deputados.
Flávia Simone Pereira De Sousa (Brasil)

Graduada em Comunicação Social - Jornalismo, trabalha na área de assessoria de comunicacãão

\section{Introdução}

O cenário mercadológico da comunicação está em fase de mudança. Com o avanço da tecnologia, a mídia impressa cresce menos que outras mídias. Diante deste novo contexto, surgem questionamentos em relação à continuidade da existência da mídia impressa.

É possível verificar que diversos jornais impressos deixaram de circular, e os que ainda sobrevivem, estão vendendo menos exemplares com o passar dos anos.

Um dos grandes jornais do Brasil que abandou a versão impressa foi o Jornal do Brasil. Um jornal carioca, conhecido nacionalmente, que era 
referência para outros jornais e para vários jornalistas. Essa transição acendeu muitas discussões. A direção do $J B$ afirmava que estava acompanhando o desenvolvimento da tecnologia e que esse seria o futuro de todos os jornais. Em contrapartida, organizações criadas para defender os interesses da mídia impressa afirmavam veementemente que esse acontecimento se restringia ao Jornal do Brasil e que os motivos que ocasionaram essa mudança em nada tinham a ver com o avanço tecnológico.

Diante disso, esse artigo pretende responder quais motivos levaram o Jornal do Brasil, um dos maiores jornais do país, a extinguir sua versão impressa e ir para o meio digital? Assim, é objetivo deste artigo verificar que elementos culminaram no fim da versão impressa do $J B$.

Segundo artigo publicado pela Associação Nacional dos Jornais (ANJ), a imprensa brasileira nasceu tardiamente. Isso se deveu a problemas relacionados a um país que nasceu como colônia de exploração. Aqui no Brasil, o ingresso do ensino superior, a abolição da escravatura, a isonomia política surgiu muito depois do que em outros países, o que contribuiu para o analfabetismo e para a concentração de renda. Fatores que limitaram a evolução da imprensa, uma vez que impediam que existisse aqui um percentual de leitores semelhantes aos existentes em outros países.

Existem registros de que no Peru os impressos já circulavam desde 1594. Porém na América Latina, somente no século XIX surgiram jornais com periodicidade regular, perfis informativos e duradouros.

Dessa maneira, esse artigo se justifica pois traz uma profunda revisão bibliográfica sobre a história de um dos mais importantes jornais brasileiros que extingue sua versão impressa e que inquieta pesquisadores, já que os documentos que versam sobre o $J B$, a migração para a web e o fim do impresso, a rigor, não se encontram organizadas e as fontes de informação, inclusive, jornalistas que trabalharam no $J B$ evitam falar no assunto.

\section{História da imprensa no Brasil}

No Brasil, existem duas datas como marcos fundadores, em $1^{\circ}$ de junho de 1808, foi lançado em Londres, o Correio Braziliense, e a Gazeta do Rio de Janeiro foi criada em 10 de setembro do mesmo ano. Não existe um consenso em relação a qual dos dois seria o precursor. 
O Correio Braziliense foi publicado ininterruptamente em Londres até 1822, era um jornal mensário em língua portuguesa e livre de censura. Já a Gazeta do Rio de Janeiro foi criado para ter uma periodicidade semanal, uma semana depois de sua criação, passou a ser bissemanário. Em tempos de censura, a Gazeta tentou se apresentar como um jornal independente. Em seu primeiro número afirmava que o governo não respondia pelo jornal.

Esta gazeta, ainda que pertença por privilégio aos oficiais da Secretaria de Estado dos Negócios Estrangeiros e da Guerra, não é, contudo, oficial e o governo somente responde por aqueles papéis que nela manda imprimir em seu nome. (Gazeta, 1808)

A situação da imprensa brasileira só foi alterada em 1821, por decisões das Cortes Portuguesas, as restrições diminuíram. Em meio à independência, surgiu a imprensa política, e José da Silva Lisboa criou um jornal totalmente privado.

Em 1824 foi criada a primeira constituição brasileira que foi outorgada por D. Pedro I, foi estabelecida a liberdade de imprensa, depois foram incluídas limitações, a imprensa teria restrições e estaria sujeita a represálias.

O Diário de Pernambuco, de 1825, o Jornal do Commercio, fundado em 1827 no Rio de Janeiro e Monitor Campista criado em 1834, são jornais que surgiram nesta época e permanecem em circulação até os dias atuais.

A imprensa brasileira enfrentou vários desafios, o seu desenvolvimento foi prejudicado pelo fato de que o Brasil se manteve como uma sociedade rural, a estrutura política era conservadora. Em 1840, cerca de 85\% da população era composta de analfabetos, número no qual estavam inclusos os proprietários de terras.

$\mathrm{Na}$ segunda metade do século XIX, o desenvolvimento dos jornais foi intensificado. Os títulos mais fortes mudaram seus formatos, abandonaram o tamanho pequeno, e adotaram formas mais modernas. Nesta época foram construídos prédios especificamente para abrigar as redações.

Hoje existem poucos jornais que foram criados neste período e continuam em circulação. Entre os títulos cariocas permanecem o Fluminense e o Jornal do Brasil que foi excluído do Índice de Verificação de Circulação em 2007 (IVC) e hoje permanece com uma versão online do jornal. Ainda é 
possível encontrar os seguintes periódicos paulistas: A Província de São Paulo (atual O Estado de S. Paulo) e A Tribuna. Permanece também o jornal gaúcho Correio do Povo.

\section{O Jornal do Brasil}

Criado no Rio de Janeiro por Rodolfo Sousa Dantas e Joaquim Nabuco, em 1881. Passou a ser dirigido por Rui Barbosa em 1893. Até tornar-se propriedade do empresário Ernesto Pereira Carneiro em 1919, o Jornal do Brasil teve diferentes donos. É o que afirma Abreu (2003) no capítulo "Jornal do Brasil - Uma reforma famosa". Segundo a autora, os temas abordados pelo impresso em seus primeiros anos eram a política e a literatura. Com isso, o JB conseguiu um grande prestigio.

Lançado no dia 9 de abril de 1891, $60^{\circ}$ aniversário do Te-Deum em ação de graças pela aclamação do imperador d. Pedro II, o jornal começou com oito páginas e tiragem de $5 \mathrm{mil}$ exemplares. Em 1906, inspirando-se na experiência de importantes jornais estrangeiros, como o $\mathrm{New}$ York $\mathrm{He}$ rald, The Times e La Nacion, passou a publicar, durante vários anos, os anúncios na primeira página. E a Revista da Semana, primeira publicação nacional a empregar o processo foto-mecânico, que favorece o desenvolvimento da fotorreportagem, começou a circular, em 1900, como suplemento ilustrado do jornal. (Biblioteca Nacional Digital Brasil, 2012)

$\mathrm{Na}$ década de 1930 devido às dificuldades econômicas, o jornal transformou-se em um "boletim de anúncios", os grandes temas ficaram de lado e suas primeiras páginas eram ocupadas por classificados. Nessa época, o jornal foi apelidado de "o jornal das cozinheiras" pelo fato de que grande parte das pessoas que buscavam empregados domésticos realizavam seus anúncios no Jornal do Brasil. Abreu revela ainda, que a primeira grande mudança ocorreu em 1949 quando o advogado Manoel Francisco do Nascimento Brito foi convidado para ser consultor jurídico do Jornal do Brasil e da Rádio Jornal do Brasil. Acabou então o boletim de anúncios. $\mathrm{O} J B$, ao contrário da maioria dos jornais da época, não se influenciou por partidos políticos, tentaram se distanciar dos mesmos, adotando uma posição isenta em relação aos acontecimentos mais alarmantes que mobilizaram a sociedade. Esse foi um dos motivos que deu a ele uma enorme credibilidade, que passou então a 
ser considerado pela elite mundial. O Jornal do Brasil manteve-se como um órgão "católico, liberal-conservador, constitucional e defensor da iniciativa privada. (Abreu, 2003, p. 72)

Vários jornalistas saíram do $J B$ em dezembro de 1959, entre ele Odylo Costa Filho, ainda assim a reforma continuou sendo feita. Almicar de Castro foi o responsável pela mudança gráfica que o jornal sofreu neste mesmo ano.

O Jornal do Brasil sempre teve parque gráfico atualizado, realizou diversas reestruturações e absorveu diversas mudanças. Em 1912 ele foi pioneiro no Brasil ao lançar uma página inteira ilustrada sobre esporte.

A fotografia foi publicada na primeira página em março de 1957, ainda assim, junto com vários anúncios. O que foi alterado somente em 1959, quando a primeira página foi modificada e passou a ter como destaque as notícias. Os classificados ficaram localizados em duas bordas com formato em "L". Mais tarde esses anúncios seriam exibidos em um caderno próprio. Foi criado também um caderno destinado à cultura, voltado principalmente para o teatro e cinema. Essa reforma foi concluída em 1961.

Alberto Dines assumiu a direção da publicação em 1962 e foi o responsável pela consolidação da reforma, ele reestruturou a redação e estipulou reuniões regulares. Foi determinação de Dines que existissem editorias e fotografias nos textos, que na época não existiam. $O J B$ ocupou um lugar privilegiado na imprensa carioca, foi um grande formador de opiniões e inspirou outros jornais brasileiros com sua reformulação gráfica e editorial.

Abreu (2003) questiona Dines em relação às novas tecnologias, às mudanças que elas ocasionaram na imprensa e se estas mudanças serviram para melhorar a qualidade dos jornais brasileiros, Dines respondeu: Não, aqui no Brasil foi o contrário. A tecnologia, que deveria significar avanços de qualidade ou de tempo, aqui no Brasil não representou melhora de qualidade, ao contrário: os jornais hoje fecham mais cedo, são feitos num período de tempo muito mais curto do que na minha época. Estou cansado de dizer isso. Inventaram que eles têm que ser jornais nacionais, coisa que efetivamente não são, e que têm que estar ar sais da manhã em vários lugares. O conceito nacional, hoje, é um triangulo: Minas, Rio e São Paulo. Um pouquinho de Brasília também. Os jornais 
têm que estar cedo nesses lugares, portanto têm que rodar mais cedo, $\mathrm{e}$ têm que fechar mais cedo. O tempo para fazer fica muito menor. Hoje, os jornais fecham depois do Jornal Nacional. Assistem ao Jornal Nacional e fecham. (Abreu, 2003, p. 165).

Uma pesquisa rápida na internet pode trazer diferentes resultados que menciona a transição da versão impressa do $J B$ para a online. Apesar disso, é difícil encontrar dados mais precisos que contem a história de um dos jornais mais importantes do Brasil. Em livros, artigos e citações é possível encontrar autores enfáticos em afirmar o pioneirismo do $J B$ ao migrar totalmente para o meio online, contudo dificilmente algum deles explica que motivos o levaram a isso e a posterior extinção da versão impressa.

A verdade é que, um dos fatores aparentemente preponderantes - o financeiro - parece ser definidor. Antes de migrar para a internet, o Jornal do Brasil já tinha passado por outras crises financeiras. É o que podemos constatar em um artigo publicado na página da Hemeroteca Digital. A publicação afirma que mesmo com a frágil situação financeira e suas dívidas, no ano de 2000, o JB começou com uma tiragem média de 76 mil exemplares.
No ano de 2001, o uso da marca Jornal do Brasil foi arrendado por 60 anos à Companhia Brasileira de Multimídia, o maior acionista da empresa era o empresário Nelson Tanure que assumiu a presidência do jornal.

Ainda segundo o artigo, no ano de 2003, foi iniciada uma série de medidas de recuperação do $J B$, o que culminou no aumento da tiragem média do jornal para cerca de 100 mil exemplares em 2007. Com a aparente recuperação, em 2006 o jornal inovou ao modificar o tamanho do impresso, com dimensões menores, mas ainda assim maiores do que o formato tabloide.

Em 2008, o $J B$ tinha uma tiragem de cerca de 95 mil exemplares, no ano de 2010 o jornal entra em uma nova crise e a tiragem diária despenca para apenas 20 mil exemplares.

Há décadas em crise financeira, com falhas de gestão, queda de circulação, falta de meios de superar sua concorrência e crescimento de dívidas fiscais e trabalhistas, o $J B$ tinha dificuldades para manter o seu custo operacional de cerca de $\mathrm{R} \$ 3$ milhões por mês - adicionando-se $a$ isso um passivo estimado em $\mathrm{R} \$$ 100 milhões em dívidas. (Biblioteca Nacional Digital Brasil, 2012) 
Ainda segundo informações do artigo da Hemeroteca Digital, em março de 2010, período com maior índice de queda de circulação, Nelson Tanure contratou Pedro Grossi Jr. para gerenciar o periódico. Mesmo com essa tentativa, a única solução eficaz que Tanure encontrou para combater a crise foi extinguir a edição impressa do diário. Ele manteve 150 funcionários que iriam trabalhar na versão online

Pedro Grossi Jr. pediu licença do seu cargo por discordar com a mudança. A família Nascimento Britto, antiga proprietária e dona formal da marca afirma que não tinha conhecimento da decisão de Tanure.

No dia $1^{\circ}$ de setembro de 2010 publicou em sua página na Web a decisão que entristeceu diversos jornalista, entre eles Miriam Leitão, que foi editora de economia do renomado jornal. Um dia antes da publicação da página do $J B$ na internet, Leitão fez uma homenagem ao impresso no programa "Bom dia Brasil da Rede Globo.

"Hoje é um dia triste para a imprensa brasileira. O Jornal do Brasil, um dos mais tradicionais do país, deixa de circular na versão impressa. Agora ele só poderá ser lido na internet". (Leitão, 2010)
$\mathrm{Na}$ reportagem a jornalista, que trabalhou no JB como colunista de economia, destaca a história do jornal e suas conquistas e lembra também o nome de grandes jornalistas que passaram por lá, entre eles Carlos Castello Branco, que Leitão afirma ser o maior colunista político que o Brasil já teve.

\section{Do JB online ao}

\section{Jornal do Brasil na web}

O Jornal do Brasil sempre inovou em sua versão impressa. Foram realizadas muitas transformações gráficas em suas diferentes fases. O investimento na modernização do parque gráfico do jornal era alto. Sua versão digital também passou por modificações. Desde sua inserção no ambiente online até a exclusão de sua versão impressa, o $J B$ alterou por diversas vezes seu produto digital. As evoluções podem ser observadas a partir da análise das páginas do site ao longo de seus 15 anos.

Em 1995, o acesso à internet era restrito a poucos, além de custar caro, a velocidade era baixa, o que impossibilitava que sites tivessem imagens, vídeos e outros itens que tornariam o carregamento das páginas impossível. Foi nessa época que entrou no ar o JB Online. 
O Jornal do Brasil foi o primeiro no Brasil a divulgar notícias no espaço virtual, em 1995. Outros jornais acompanharam o movimento posteriormente.

Mesmo com diversas transformações ao longo de sua existência, no início dos anos 1930, o JB já estava imerso em uma grande crise financeira. Apesar disso, ele adentrou os anos 2000 com uma tiragem média de 76 mil exemplares.

Segundo publicado pelo jornal laboratório da PUC-SP, em 1960 foi iniciada a construção de um novo prédio pelos proprietários do jornal, a obra foi iniciada na Avenida Brasil e foi responsável pelo aumento das dívidas financeiras da empresa. O prédio é considerado o símbolo da ascensão e da queda do $J B$. Passavam a integrar a equipe jornalística do periódico grandes nomes na imprensa, como o autor do vídeo "Avenida Brasil 500", o fotógrafo Rogerio Reis.

Com a redução de anúncios, em 1982, as primeiras páginas do jornal, que eram ocupadas por classificados, passam a ser utilizadas para exibir o índice, Neste mesmo ano, o Brasil passava por uma grande crise econômica
Os anos 1980, na América Latina, ficaram conhecidos como "a década perdida", no âmbito da economia. Das taxas de crescimento do PIB à aceleração da inflação, passando pela produção industrial, poder de compra dos salários, nível de emprego, balanço de pagamentos e inúmeros outros indicadores, o resultado do período é medíocre. No Brasil, a desaceleração representou uma queda vertiginosa nas médias históricas de crescimento dos cinquenta anos anteriores. (Marangoni, 2012)

O mau momento da economia do país juntamente com erros administrativos foi determinante para piorar a crise do $J B$, as dívidas do jornal tornaram-se impagáveis

Em 2001, a família Nascimento Brito arrenda o título do periódico para Nelson Tanure por 70 milhões. Ao assumir a presidência do jornal, Nelson Tanure retoma o JB ao local de sua antiga sede, que estava localizada na Avenida Rio Branco. Anos depois ele iria instalar a redação do jornal na Casa do Bispo, localizado no bairro do Rio Comprido.

A marca Jornal do Brasil passou a ser utilizada pela Companhia Brasileira de Multimídia. A antiga empresa, Jornal do Brasil S.A. ficou com 
várias dívidas trabalhistas e previdenciárias, além das dívidas bancárias. O valor estimado era de cerca de R\$ 750 milhões.

A empresa continuou em poder da família Nascimento Brito e ficou com sua sede no mesmo local, a zona portuária da cidade. Posteriormente a empresa entrou com o processo de adesão de Refis, que permitiu que a dívida com a Receita Federal fosse financiada. Esse valor de $10 \%$ a 15 do valor total que a empresa devia, acrescido a esse montante estavam os juros e outras taxas de refinanciamento.

Segundo divulgado pela Folha de São Paulo, a outra parte da dívida era trabalhista. A empresa não estava mais pagando o INSS e nem depositando o FGTS dos funcionários. Parte desses valores está com pagamento pendente até hoje.

Ainda em 2001, Tanure desenvolveu uma série de medidas para recuperar o JB. Segundo matéria divulgada pela jornalista Cristina Grillo, da Folha de São Paulo, o objetivo dessa reestruturação era recuperar o prestígio de décadas passadas. $\mathrm{O}$ projeto sugeria mudanças editoriais e modernização tecnológica.

Na ocasião Nelson Tanure informou a Folha de São Paulo sua pretensão: "Vou integrar o "JB" ao mundo virtual, investindo em equipamentos e em gente qualificada".

Outra mudança proposta foi na linha editorial, o jornalista Mario Sergio Conti assumiu o cargo de diretor de redação e propôs a criação de um jornal menor, além de uma redução no número de cadernos, que deveriam conter textos mais elaborados e reportagens mais profundas.

Tanure tinha a intenção de deixar o $J B$ mais atrativo e dessa maneira atrair olhares de investidores estrangeiros. Para ele a emenda constitucional que permitiria a participação do capital estrangeiro em empresas de comunicação seria aprovada. O novo dono da marca tinha a intenção de aumentar a tiragem do jornal, como consequência do aumento de vendas que era previsto por ele. Durante a semana o jornal vendia 70 mil exemplares, Tanure pretendia elevar esse número para os 100 mil e aos fins de semana aumentar o número de 105 mil para 140 mil. Outro objetivo do empresário era o de investir na aérea de tecnologia. Essas transformações seriam implantadas gradualmente, para que o leitor fosse se habituando.

Em 2006 o periódico passou por um processo de modernização gráfica, seu formato tradicional standard foi mudado para berliner, que 
possuía dimensões menores, mas ainda assim, maiores do que o formato tabloide. Os vários cadernos diários foram condensados em apenas dois. No primeiro, seria o caderno A, onde estaria o noticiário "quente": economia, política, internacional, esportes e cidade. O segundo foi o Caderno B, que possuía espaço para saúde, moda, comportamento, estilo.

Em 2007 a tiragem do jornal aumentou para cerca de 100 mil exemplares. No mesmo ano, Tanure lançou a JBTV, que durou apenas seis meses.

A circulação do jornal em 2008 mantinha-se em torno de $95 \mathrm{mil}$ exemplares. Essa boa fase durou pouco tempo, o periódico entrou em uma nova rota de queda: em 2010, a tiragem diária caíra para apenas $20 \mathrm{mil}$ exemplares.

$O J B$ possuía um gasto mensal de 3 milhões de reais por mês, além de um acúmulo de passivo estimado em 100 milhões de reais em dívidas. "Há décadas em crise financeira, com falhas de gestão, queda de circulação, falta de meios de superar sua concorrência e crescimento de dívidas fiscais e trabalhistas, $\mathrm{o} B \mathrm{~B}$ tinha dificuldades para manter o seu custo operacional". (Biblioteca Nacional Digital Brasil, 2012)

Mesmo com todas as transformações implantadas por Tanure, em
2010, o Jornal do Brasil publicou um comunicado informando o fim de sua edição impressa. O conteúdo do jornal passou a ser disponibilizado somente na internet, $\mathrm{o}$ assinante pagava $\mathrm{R} \$ 9,90$ por mês, uma economia de $\mathrm{R} \$ 40,00$, já que a assinatura do impresso era $\mathrm{R} \$ 49,90$.

O empresário negou que essa transição de mídias tenha acontecido por motivos financeiros. Em comunicado, Tanure afirmou que a decisão foi tomada após uma consulta eletrônica com os leitores, que apoiaram a mudança.

Além do JB, em 2003 Nelson Tanure arrendou o jornal econômico Gazeta Mercantil, outro periódico que estava em crise. Porém a marca foi devolvida para o antigo dono, depois que o jornal deixou de funcionar. O empresário possui ações da Tim Participações.

O jornalista Fernando Gabeira na data de extinção da versão impressa do $J B$ destacou a importância do impresso, afirmando que o sonho profissional daquela juventude era trabalhar no jornal. Gabeira citou ainda as inovações feitas pelo periódico.

O desenho do jornal, trabalhado por Amílcar de Castro e inspirado no pintor holandês Mondrian, 
representou durante muito tempo uma atração internacional, porque muitos jornalistas vieram do exterior para observar aquelas mudanças. Na parte cultural, o Jornal do Brasil inovou lançando um suplemento literário voltado para o concretismo, mas que revelou alguns dos principais poetas e escritores do país. (Gabeira, 2010).

O jornalista afirmou que o $J B$ já estava morto: "Nos últimos anos, o Jornal do Brasil tornou-se um fantasma do que era, conservando a máxima de que um jornal leva mais de uma década para morrer".

A última edição do $J B$, publicada na terça-feira de 31 de agosto, não foi especial, a publicação não tinha o objetivo de indicar um fim, queria apenas sinalizar uma mudança.

Na publicação foi apresentado ao leitor o futuro do $J B$, a nova fase foi destacada sob o título " $J B$ Digital vai estrear com artigo de Lula”, segundo o texto apresentado, a equipe do jornal seria composta por 150 funcionários

Como justificativa para o fim de sua versão impressa, o $J B$ ressaltou que os leitores optaram pela transição "Nesta era de leitores digitais e de internet, acrescida pela problemática ecológica, a ampla consulta que realizamos sobre o futuro confirmou que a maioria quer modernidade". $\mathrm{O}$ jornal que enfatizou o fato de ser o primeiro a ter uma versão na internet, citou ainda que oscustos econômicos e ambientais do papel são insustentáveis.

Segundo foi publicado, a linha editorial não seria modificada. "Apesar do que vêm propagando alguns poucos mal informados, o Jornal do Brasil está caminhando para uma nova e melhor fase".

Imagem 1. Última capa do Jornal do Brasil.

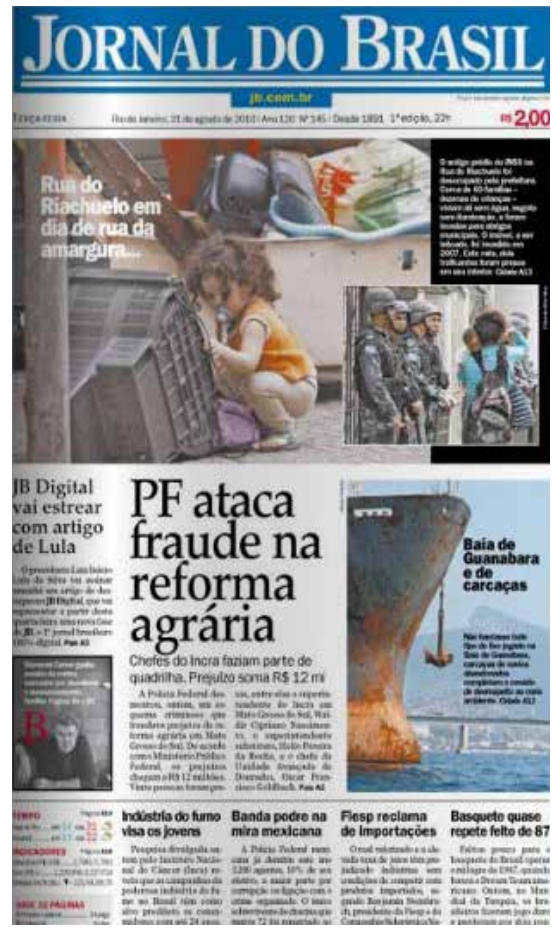

Fonte: RUSSO, 2010. 
Além da alusão ao término do impresso. A capa da publicação exibiu uma criança brincando enquanto acontecia uma ação policial para a desocupação de um prédio do INSS no centro do Rio de Janeiro.

Foi apresentada também uma manchete sobre a fraude da reforma agrária descoberta pela Polícia Federal. Essa operação foi responsável pela prisão do superintendente do Incra no Mato Grosso do Sul, na época, Waldir Cipriano do Nascimento. Outra matéria que foi destaque na primeira página foi a de carcaças de navios na baía de Guanabara.

\section{Um possível retorno}

\section{do impresso}

Em janeiro de 2012, o Jornal do Brasil publicou em sua página uma pesquisa onde afirmava que $79 \%$ dos leitores aprovavam uma possível volta do $J B$ ao papel. A enquete foi realizada pelo Portal Imprensa, que concluiu que a maioria dos leitores do site acreditavam no sucesso da iniciativa. Foram computados mais de 3 mil votos, dos quais $16 \%$ não pensavam que a volta do $J B$ seria bem sucedida.

Mesmo divulgando essa pesquisa em seu portal, o Jornal do Brasil nunca chegou a se pronunciar sobre um possível retorno da versão impressa, que segundo o site "o repórter" divulgou em dezembro de 2011, voltou a ser pensada após a recontratação de Pedro Grossi. O texto explica que o jornal teria uma periodicidade semanal. O diretor de assuntos institucionais, Reinaldo Paes Barreto, informou a publicação que ainda não estava nada decidido, "É um projeto, que dependerá de dinheiro, de vários fatores. Não tem nada certo. Tudo dependerá de pesquisa e recursos".

O retorno da versão impressa ainda não aconteceu e a direção do jornal não possui uma definição sobre uma possível retomada.

\section{Fim das notícias em papel}

No final do ano de 2012, o Observatório da Imprensa exibiu um programa pela TV Brasil com a intenção de discutir sobre o futuro do jornal em papel. Sobre a direção do jornalista Alberto Dines, vários jornalistas se reuniram diante das câmaras para compartilharem opiniões acerca do tema proposto. São eles: Luiz Fernando Gomes trabalhou no Jornal do Brasil e em O Dia. Durante três anos foi editor-executivo do Jornal da Tarde, Luiz Fernando Gomes e Pedro Doria. Pedro Doria é editor executivo de plataformas digitais e colunista de $O$ Globo. Foi editor-chefe de conteúdos 
digitais de O Estado de S. Paulo e colunista da Folha de S. Paulo.

O programa contou com a presença de Marion Strecker, fundadora do UOL e colunista da Folha. Marion trabalhou por 12 anos na Folha, onde foi crítica de arte, editora da Ilustrada e repórter especial. Liderou o processo de informatização do Banco de Dados e outros projetos de uso intensivo de tecnologia para fins jornalísticos e foi coautora do Manual da Redação da Folha. Na abertura do debate Dines explicou que a mídia está em má fase.

A pujança da nossa civilização nos últimos milênios apoiou-se paradoxalmente num produto extremamente frágil, vulnerável, perecível: o papel. E o papel, segundo anunciam as 'cassandras', está com os dias contados. O que antes funcionava no espaço e medido em centímetros, agora foi transformado em bits, bytes, impulsos armazenados em chips microscópicos ou nas nuvens. (Dines, 2012)

O criador e atual presidente do $E l$ País, Juan Luís Cebrián afirmou que morrerá fazendo jornais em papel. Para Cebrián, o anúncio feito pelo professor Philip Meyer, que afirma que os jornais de papel irão desaparecer na década de 2040 se refere ao desaparecimento de pessoas que queiram comprar os jornais e, paralelamente, dos sistemas de distribuição.

É evidente o desaparecimento do suporte de papel para os meios de informação. Mas as mudanças estão muito aceleradas este ano e no ano passado. Eu creio que, sobretudo para os jornais de referência, de qualidade, como El País, The New York Times e Le Monde, acabe ou não o suporte em papel, durarão bastante tempo. Estimo que mais de duas décadas - ainda que diminuam os números em circulação, sejam mais caros e se dirijam a uma elite. E seguirão servindo para organizar um pouco o ciberespaço, onde há muita confusão. Portanto, creio que vai diminuindo a presença dos jornais impressos, sobretudo os de qualidade. (Cebriàn, 2012)

Cebrián afirmou que nos Estados Unidos existem jornais que duraram mais de cem anos e recentemente pararam de circular, é o caso do Christian Science Monitor, ele afirma ainda que existem milhares de pessoas que não tem acesso ao jornal em papel

O desemprego é de 40 mil jornalistas nos Estados Unidos nos últimos 
anos, 7 mil na Espanha. É uma mudança revolucionária nos meios de comunicação. Estamos sendo testemunhas que a internet é uma mudança na civilização e afeta os hábitos dos consumidores muito mais do que imaginávamos. (Cebrian, 2012)

O diretor do Knight Center of Journalism in the America (da Universidade do Texas, em Austin), Rosental Calmon Alves, afirmou que os jornais precisam ter uma plataforma na Web e que não existe mais a possibilidade dos jornais continuarem fazendo suas publicações somente em um suporte físico. "O jornal hoje já é um híbrido de átomos e bits. Qualquer jornal hoje é inconcebível que não tenha a sua presença digital na internet $\mathrm{e}$ em outras plataformas. Existe já uma transformação do negócio do jornal, do papel que o jornal exerce na vida das pessoas". (Alves, 2012)

Segundo Rosental Calmon Alves a penetração do jornal impresso já vem diminuindo há seis décadas. Esse processo ficou mais intenso com a revolução tecnológica.Ojornalista destaca que o principal problema é o desinteresse das agências publicitárias nessa antiga plataforma. Segundo Alves, a circulação dos jornais não está diminuindo, o que está acontecendo é que os publicitários estão preferindo anunciar em outras mídias, desfalcando assim as finanças da mídia impressa. "Não é a circulação que está desabando de uma hora para a outra. É a publicidade que está saindo". (Alves, 2012)

O professor titular da Escola de Comunicação da Universidade Federal do Rio de Janeiro, Muniz Sodré, explica que com o avanço da internet, o jornalismo analítico e crítico acabaram e que as pessoas não estão mais interessadas nesse tipo de linguagem, Agora os leitores recebem um número bem maior de informações, porém são notícias superficiais, todos falam o que pensam, é um jornalismo na maioria das vezes sem credibilidade. "A internet é anárquica, caótica. A informação que passa ali é um falatório. É a coisa mais superficial, mais anódina, mais boba do mundo. Mas esse julgamento que estou fazendo ainda é o julgamento de quem tem a cabeça do jornal papel”. (Sodré, 2012) Já para o executivo de plataformas digitais de O Globo, Pedro Doria, não existem motivos para ficar aflito com o fim do jornal em papel. Ele afirma ainda que as notícias divulgadas no meio online não são necessariamente superficiais. Segundo 
Doria existem várias publicações na Web de longas reportagens e de outros estudos analíticos.

Eu vou morrer trabalhando em uma redação. A única preocupação que realmente tenho não é se o jornal vai acabar ou não - a minha intuição é de que não vai acabar, mas se acabar não tem problema. O importante é ter uma redação experiente, muitas redações experientes, não para levantar opinião, mas para levantar informações sobre o que os governos estão fazendo, o que a sociedade está fazendo, o que está acontecendo. É isso, no fim das contas, que sustenta a democracia. (Doria, 2012)

A crise vivida pela mídia não é consequência apenas do avanço das tecnologias, existe a instabilidade econômica que o mundo ocidental está vivendo. Não é somente o setor da comunicação que está sentido esta instabilidade, existem altos índices fechamento de empresas de diversos setores. É possível constatar isso ao verificarmos que a crise dos jornais é mais grava na Espanha e Estados Unidos, que foram países que sofreram mais com esse impacto financeiro. "Veja a curva do fechamento dos jornais americanos. Em 2007, um jornal fechou. Em 2008 foram quarenta e poucos. Em 2009, cento quarenta e tantos. Quando você chega em 2010 cai para a casa de 20". (Doria, 2012)

O jornalista, Luiz Fernando Gomes, editor dos veículos do grupo Lance!, afirma que o jornalismo bem feito, independente de qual plataforma utiliza, mesmo com a multiplicação de fontes de informação, sempre terá um espaço na sociedade, porque mesmo com a grande divulgação de informações, ainda é difícil encontrar um jornalismo de qualidade.

Álvaro Caldas afirma que o jornal no futuro chegará aos leitores via Internet, televisão inteligente (combinação da TV com o computador) e pelas diferentes formas de TV paga. Ele explica que mesmo abalado em sua estrutura, o jornal impresso sobreviverá mais uma vez, e o que o principal desafio será mudar preservando seus valores e suas principais características.

Leitores de jornal e usuários da internet têm interesses e curiosidades diferentes. Para assegurar seu espaço, caberá ao jornal do presente investir naquilo que o leitor espera encontrar nele: originalidade, texto interpretativo e analítico, com suas implicações e possíveis repercussões na vida de 
cada um. $\mathrm{O}$ fato situado dentro de um contexto mais amplo, ao lado de pesquisa e opinião. Já na internet o que se busca são informações rápidas e específicas, em poucas linhas. (Caldas, 2002, p. 17)

\section{Um jornal que fez história}

O Jornal do Brasil fez história, foi um dos periódicos mais importantes do país. Segundo informações da ANJ, no fim dos anos 1980, vendia mais de 180 mil exemplares por dia de semana e 250 mil aos domingos.

Suas reformas gráficas, como a que aconteceu em 1959, serviram para nortear a imprensa dentro e fora do Brasil. Amílcar de Castro, inovou quando eliminou os fios entre as colunas e criou a diagramação vertical. No mesmo ano, ocorreram mudanças no plano editorial, além da criação de suplementos, que até então eram inexistentes na imprensa brasileira. A equipe que contava com os jornalistas Carlos Lemos, Odylo Costa e Janio de Freitas, foram os responsáveis por tonar os textos mais leves.

Alberto Dines chegou ao Jornal do Brasil pouco tempo depois da grande reforma gráfica, mas para ele o $J B$ ditou tendência "A reforma de 59 foi a mais duradoura da imprensa brasileira. Inspirada em padrões estéticos criativos, como o concretismo, antecipou tendências. Uma revolução no design, que inspirou os jornais sem fios".

Durante o regime militar, com uma capa histórica, o jornal teve um papel decisivo. Em 1968, dia seguinte ao decreto do Ato Institucional número 5 (AI-5), diante da grande repressão e a impossibilidade de manifestar sua opinião diante dos fatos. $\mathrm{O} J B \mathrm{pu}$ blica no canto esquerdo de sua capa sua indignação diante do governo militar, com a simulação de uma previsão do tempo ele criticou: "Tempo negro. Temperatura sufocante. O país está sendo varrido por fortes ventos. Mínima 5 graus no Palácio Laranjeiras. Máxima 37 graus em Brasília”.

Para o jornalista Orivaldo Perin, que entrou no $J B$ como estagiário, $o$ jornal revolucionou a imprensa brasileira, ele afirma que nos anos $60 \mathrm{e}$ 70 era o modelo a ser seguido, tanto gráfica como editorialmente. "Sua importância estava mais no conteúdo que na tiragem. A venda média do jornal, mesmo nos áureos tempos, ficava entre os 100 mil e os 150 mil exemplares/dia, mas tudo o que publicava, repercutia”.

Alberto Dines, destaca que a disputa existente entre os dois maiores jornais cariocas, O Globo e o Jornal do Brasil, foi muito importante. Para 
ele, a concorrência obrigou o aperfeiçoamento, pois eles eram obrigados a entrar na seara do outro, isso estimulou um bom jornalismo e a evolução no conteúdo. "Foi um dos momentos mais bonitos da história do jornalismo brasileiro. Quem ganhou foi o leitor", afirma Dines.

Quem também concorda que a concorrência entre os dois jornais foi boa, é a jornalista Miriam Leitão, que narra em um vídeo, como era bom o desafio de fazer um jornal melhor do que $O$ Globo. Ela e vários outros jornalistas afirmam que sempre sonharam em participar da redação do $J B$ e que foi lá que aprenderam a fazer um jornalismo de verdade.

A jornalista Adriana Bittencourt compartilhou sua história com o Jornal do Brasil, periódico que aprendeu admirar desde criança

O 'JB' despertou, em mim, a vontade de ser jornalista. Desde pequena, pegava a edição comprada pelo meu pai para ler as matérias e admirar as fotos. E ficava ouvindo ele falar como o jornal era bom e sua leitura diária indispensável. Sabia que lá estavam os melhores jornalistas e as melhores notícias. E que ter seu nome assinando uma daquelas matérias era sonho de todo e qualquer profissional de comunicação. Assim, na época do vestibular não tive dúvidas: optei por Comunicação Social para, finalmente, conseguir trabalhar ao lado daqueles jornalistas que eu tanto admirava, no prédio do jotinha na Avenida Brasil, 500. Já no terceiro período da UFF consegui um estágio no JB Online, o primeiro jornal brasileiro na internet. Participava de mais um dos pioneirismos do JB. No meu primeiro dia de trabalho, chorei ao passar pela porta da redação. Finalmente, eu fazia parte daquele jornal que sempre admirei. Muito mais do que à faculdade que, sim, me ensinou muita coisa, devo ao $J B$ parte importante da minha formação profissional. Fui contratada pela redação depois de formada e foi lá, durante pouco mais de quatro anos, que aprendi o quanto é importante ser ética, imparcial, justa com os colegas de trabalho e obstinada pela comunicação correta e eficaz.

(Bittencourt, 2010)

Ainda segundo Bittencourt (2010), com o fim do $J B$, o país perdeu uma referência, os leitores perderam um enfoque e os estudantes perderam a oportunidade de participar de um dos maiores e mais respeitados veículos de comunicação do mundo. 
O fato do Jornal do Brasil ter modificado a história da média impressa, é consenso entre jornalistas que por lá passaram e também por outros que acompanharam o periódico ao longo dos anos.

Flávio Pinheiro começou a trabalhar no JB em 1977 como subeditor de economia, porém permaneceu lá por pouco mais de um ano, em 1985 retornou ao jornal como editor do Caderno B. Em entrevista concedida a Associação Brasileira de Imprensa, o jornalista falou sobre sua experiência no periódico.

Conheci no $J B$ esplêndidos profissionais já escolados em outras redações, como Miriam Leitão, William Waack, Ruth de Aquino... Foi um período de muitos prêmios (como o Esso de Jornalismo de Zuenir Ventura, pela cobertura do caso Chico Mendes) e de grande fertilidade editorial, como a reformulação da revista Domingo e a criação da revista Programa e do caderno Idéias. (Pinheiro, 2006)

Os jornalistas que passaram pelas redações do $J B$ concordam que o jornal teve uma morte gradativa, e que antes da anunciada extinção da versão impressa, o jornal apenas sobrevivia, como resultado de sua crise financeira o $J B$ perdeu o prestígio e a credibilidade. Para o ex-editor-chefe do JB, Marcos Sá Corrêa, o jornal perdeu sua originalidade.

A importância do $J B$ foi imensa. Contando só os anos do jornal que vivi ou conheci, de meados dos anos 50 e aos anos 90, acho que todo jornal no Brasil queria de certa maneira ser o JB. Mas isso passou há muito tempo. Ele é um jornal que se limitou a sobreviver nas últimas décadas. Cada vez que ele fazia um esforço para melhorar, ficava mais parecido com os outros jornais, porque sua fórmula original estava esquecida. (Corrêa, 2010)

Para Pinheiro, quando do anúncio da morte do $J B$, o jornal já estava desfigurado e irreconhecível. Alguns profissionais, no entanto, afirmam que a credibilidade acabou quando o jornal passou para as mãos do empresário Nelson Tanure. O ex-chefe de redação do $J B$, Orivaldo Perim afirma que a depois da venda do jornal, sua morte tornou-se previsível.

Antes da venda da empresa, mesmo com todos os problemas de gestão, o jornal tinha credibilidade, que 
sempre foi seu ativo mais precioso.

Os novos donos não conseguiram ou não quiseram entender isso. A venda foi um golpe forte na credibilidade da marca, e depois dela a morte do jornal nas bancas tornou-se uma questão de tempo. (Perim, 2010)

Alberto Dines, que trabalhou no $J B$ durante 12 anos, acredita que a morte do jornal aconteceu gradativamente, ele afirma que o jornal já estava mal quando completou um século de existência. A crise, segundo Dines deveu-se a erros políticos e econômicos.

Em um programa do Observatório da Imprensa, feito especialmente sobre o $J B$, exibido em 20 de julho de 2010, logo após o anúncio do fim da versão impressa, Dines expõe seu descontentamento com a frieza com que a imprensa reagiu diante do termino do $J B$ em papel. Para Dines, a falta de emoção da mídia foi fruto da transformação da imprensa em indústria.

Dines afirmou, ainda, que o Jornal do Brasil desapareceu vitimado pela conhecida falência múltipla dos órgãos.

Péssimas companhias e lamentáveis escolhas políticas liquidam criaturas e liquidam instituições. E aqui não foi diferente. Toda a imprensa apoiou o golpe militar em 64, exceto a Última Hora, mas pior do que isso foi entregar-se ao quiçá da economia Delfim Neto, apoiar Leitão de Abreu contra o General Geisel, depois aliar-se a Maluf, depois aderir a Collor de Melo e, mais recentemente, ao casal Garotinho. (Dines, 2010)

Para Dines, o que decretou a falência do $J B$ foi o envolvimento com Delfim Neto, que incentivou a construção de uma nova sede.

Amizade mais perniciosa foi com Delfim Neto que estimulou o jornal a endividar-se pesadamente para financiar uma faraônica sede e os novos equipamentos, esse elefante branco atropelou o resto dos escrúpulos e entregou o jornal ao empresário que não lê jornais, detesta jornais, excedo os jornais moribundos que arrenda a preço de banana. (Dines, 2010)

O colunista Ancelmo Gois, que trabalhou no jornal durante 6 anos, fazendo o Informe $J B$, concorda que a falência não aconteceu em 2010: O JB acabou faz tempo. Era um cadáver insepulto. Digo isso com tristeza. É difícil dizer quando exatamente o 
jornal acabou, mas, certamente, não foi agora. Em que pese o esforço quase heróico dos coleguinhas que estavam lá, o jornal já tinha perdido a alma.

O livro Jornal do Brasil: Memórias de um secretário - Pautas e fontes, foi escrito por Alfredo Herkenhoff, em setembro de 2010. Trabalhou durante 20 anos no JB. Começou como secretário até virar colunista do $\mathrm{Ca}$ derno $B$. Em sua obra, ele afirma que não é possível determinar um responsável pelo fim do $J B$.

Causas e culpas envolvendo a decadência do Jornal do Brasil demandam investigação profunda e análises múltiplas. Não consigo, pessoalmente, condenar ninguém aqui e agora. Não me sinto confortável para pretender ser a palmatória do mundo. Não tenho como definir se foi a ditadura, a concorrência ou os desmandos administrativos que levaram o $J B$ à degradação. Talvez, o conjunto desses fatores. (Herkenhoff, 2010)

Ele destaca que a concorrência com O Globo foi em parte responsável pela crise que já possuía décadas de existência.

E o que está em jogo não é a honra dos verdadeiros chefes do jornal nos últimos 50 anos: Dr. Manoel Francisco do Nascimento Brito ou seu filho, José Antonio, o Josa nos anos 90, ou do gestor da marca, Dr. Nelson Tanure, no Século 21. Poderia parecer grito no escuro qualquer tentativa de, nessa hora tão difícil, acusar e ridicularizar os três comandantes de um navio à deriva há décadas e enfrentando concorrência avassaladora de $O$ Globo a partir do nascimento e crescimento da TV Globo em 1965. O processo de decadência também é fruto de cultura do desperdício de recursos e de sua má aplicação.

O Jornal do Brasil padece de uma longa crise financeira, uma bola de neve de passivos fiscais e trabalhistas, pouca diferença fazendo definir se a dívida totaliza 100 milhões disso, ou 100 milhões daquilo, 1 bilhão de reais ou 1 bilhão de dólares. Impagável sem uma costura política que atraia capitais de forma segura. (Herkenhoff, 2010)

O autor afirma que a crise no Jornal do Brasil tornou-se perceptível a partir dos anos 80 , quando enfrentava a acirrada concorrência de O Glo$b o$, que possuía na época um grande investimento publicitário em propagandas de televisão. Os sinais de que 
o jornal não estava bem apareceram na virada dos anos 90, os bancos, que estavam dispostos a auxiliar financeiramente a família Brito, fecharam as portas para a empresa, os salários dos funcionários foram atrasados. A circulação caiu vertiginosamente.

Não foi surpresa quando, em 1995, o Banco Nacional quebrou, e ninguém noticiou que o $J B$, só a esta instituição da família Magalhães Pinto, devia cerca de 50 milhões de dólares. Pelo menos é o que o alto escalão na redação, nas internas, dizia na época. Pouco depois, quebraria o Banco Econômico, e de novo lá estava o $J B$ na lista dos maiores devedores, algo em torno de 10 milhões de dólares, sempre segundo editores com quem privei naquela correria de atualizar e melhorar a edição em cima do fechamento ou já durante a rodada, posto que ainda havia luta renhida com o concorrente $O$ Globo. Era um tempo em que o real praticamente tinha paridade com o dólar, daí porque tanto se falava em moeda brasileira quanto americana. (Herkenhoff, 2010)

Alfredo Herkenhoff destaca que diante de tantas dívidas, $\mathrm{o} B \mathrm{~B}$ não possuía dinheiro nem mesmo para pagar as rescisões de contrato de trabalho dos funcionários:

$$
\begin{aligned}
& \text { A dívida do } J B \text { virou um mistério } \\
& \text { a engordar os sucessivos rombos } \\
& \text { da impossibilidade da viúva. Cifras } \\
& \text { como óvulos estéreis. Entre tantas } \\
& \text { manobras financeiras, nada sobrou } \\
& \text { mesmo para pagamento prioritá- } \\
& \text { rio das indenizações a funcionários, } \\
& \text { como manda a lei, e não a cumpre } \\
& \text { tão bem a Justiça do Trabalho em se } \\
& \text { tratando de jornal. }
\end{aligned}
$$

(Herkenhoff, 2010)

A compra do jornal por Tanure trouxe uma certa esperança para os funcionários que ali trabalhavam, porém segundo Alfredo, o empresário investiu pouco e mal. Mesmo com o aumento das vendas em 2003, o comando da redação sofreu várias trocas, os parâmetros do jornal sofreram várias alterações, entre elas a mudança de formato, foi adotado o modelo tabloide. O que não teve o resultado esperado. O jornal chegou a ser vendido por $\mathrm{R} \$ 1$, mas nada evitou sua queda de circulação.

A falência do jornal não pode ser atribuída somente a Nelson Tanure, nenhum outro empresário poderia salvar o $J B$, acredita Alfredo Herkenhoff. 
Tanure não matou o JB. Garantiu-lhe uma frágil sobrevida de 10 anos. Apesar de todos os erros, este mérito ninguém tira do controvertido empresário baiano. Talvez ninguém concorde com minha opinião, mas mesmo no meio deste caos, notei que havia pessoas torcendo, no fundo, para um dia poder saudar Nelson Tanure como o entrepreneur que, além das aparências, contra todos os débitos e enfrentando tudo, descrédito e especialmente a própria inexperiência, saísse vitorioso dessa aventura de salvar o Jornal do Brasil, primeiro da família Nascimento Brito, depois dele próprio. (Herkenhoff, 2010)

Em seu livro, Herkenhoff destaca que a versão digital do jornal poderia ser uma forma de manter o $J B$ vivo. Contudo, ele destaca que quando o site do periódico era gratuito existiam poucas visitações à página:"era inacreditável pensar que as visitações aumentariam sendo cobrado o valor de $\mathrm{R} \$$ 9,90 para o leitor acessar o conteúdo digital". Para Alfredo o problema não era o preço e sim a falta de qualidade. O investimento no meio digital é apontado como um fator essencial para o sucesso do Jornal da Condessa na Web, a busca de experiência junto a outros sites de sucesso, também é mencionada pelo autor.
Para uma sobrevida adicional, o $J B$ precisaria de um apoio emergencial, como o que Tanure lhe deu em 2001, mas agora investimento a ser tocado a partir da experiência dos jornais digitais que mais fazem sucesso no mundo. Os portais brasileiros de maior público são poucos e bem conhecidos, são concorrentes entre si e representantes de grandes empresas num caldeirão de mexericos e notícias curtas e chapadas que emergem do sistema de clonagem total via control C, controlV. (Herkenhoff, 2010)

Alfredo atribuiu parte da culpa do fim da versão impressa do $J B$ aos políticos, segundo o autor o desaparecimento total das bancas poderia ter sido evitado, caso os Três Poderes em Brasília tivessem assumido a maior parcela do ônus:

O JB está sendo riscado do mapa das bancas porque isso parece também desejo dos ocupantes dos palácios que Oscar Niemeyer projetou no Distrito Federal, com burocratas no topo do poder desprezando o troco que a História lhes reserva por ignorarem que bom jornalismo e boa educação são as faces de uma mesma moeda chamada desenvolvimento social. (Herkenhoff, 2010) 
O possível sucesso do $J B$ no meio online era uma dúvida de muitos jornalistas e também do Sindicato dos Jornalistas do Rio de Janeiro, que reuniu dezenas de ex-funcionários do Jornal do Brasil em Cinelândia, centro do Rio, no dia 21 de julho de 2010, para protestar contra o fim da versão imprensa do periódico. Entre os questionamentos estavam as dúvidas sobre o futuro dos jornalistas que ainda trabalhavam na redação e corriam o risco de perder seus empregos além da exigência do pagamento dos direitos trabalhistas dos antigos funcionários do $J B$. Em nota publicada na página do sindicato dias antes da manifestação, a entidade lamenta o fim do Jornal do Brasil.

Na quarta-feira dia 21, ao meio-dia, haverá manifestação em frente à atual sede do Jornal do Brasil -Avenida Paulo de Frontin 568-, no Rio Comprido, para tentar evitar o fechamento daquele que já foi um dos mais importantes jornais da imprensa brasileira. Sabemos que o Jornal do Brasil de hoje nada tem a ver com aquele jornal que durante mais de um século escreveu boa parte da história do nosso país. Um jornal que ousou, que foi cantado pelos tropicalistas e acima de tudo não seguiu à risca a cartilha da ditadura militar, como outros jornais fizeram.

(Herkenhoff, 2010)

$\mathrm{Na}$ época, a presidente do Sindicato dos Jornalistas do Rio, Suzana Blass, firmou que o sindicato tinha como prioridade saber quantos profissionais continuaria trabalhando na versão online e a seguridade de que os funcionários que fosse dispensado receberiam a garantia dos direitos. Segundo divulgado pela entidade, na época do seu fechamento, o JB somava cerca de 160 funcionários, 60 deles eram jornalistas.

Mesmo com o fim do JB nas bancas, a Associação Nacional dos Jornais não acreditou em uma possível crise dos jornais impressos. Ricardo Pedreira, que permanece como diretor executivo até o atual momento, afirmou que a extinção da versão impressa do Jornal do Brasil foi um caso isolado em um momento em que havia um crescimento de circulação de exemplares da mídia impressa.

Lamentamos pelo passado do Jornal do Brasil como uma referência no jornalismo brasileiro e uma grande escola de jornalistas. Mas isso ocorreu por equívocos empresariais. A circulação dos jornais no Brasil vem crescendo, à exceção do ano passado, devido à crise, mas em 2010 vai 
voltar a aumentar. No Brasil, há muito espaço para a leitura dos jornais crescer. (Pedreira, 2010)

O então presidente da Associação Brasileira de Imprensa (ABI), Maurício Azêdo, concordou com Pedreira, destacando que a falência foi uma conseqüência.

Todos os amantes do jornalismo receberam essa informação com muita tristeza porque o $J B$, nas últimas cinco décadas, foi um ícone da imprensa brasileira. Foram cometidos vários erros que conduziram ao jornal à perda de prestígio. (Azedo, 2010)

A crise que o Jornal do Brasil enfrentou antes de decretar o fim de sua versão impressa é consenso entre todos os que participaram da história do jornal de alguma maneira, até mesmo entre os leitores. A diretoria do $J B$, nunca admitiu que existiram problemas, atribuíram a mudança de plataforma somente ao avanço da tecnologia a preservação do meio ambiente. Em nota divulgada em sua página da internet no dia 22 de agosto de 2010, é listada uma série de motivos que levaram o $J B$ a migrar para a web. Com o título "A nova fase digital do Jornal do Brasil", o texto começa destacando as seguintes características: Qualidade. Interatividade. Respeito à Ecologia. Alinhamento com o futuro. Inovação. Posteriormente é citada uma pesquisa realizada com leitores sobre a transição de plataforma. Estudo esse que nunca foi divulgado pelo Jornal do Brasil, e que foi a principal justificativa usada pela empresa para explicar os motivos que ocasionaram a mudança.

Há cerca de um mês, o Jornal do Brasil, jb.com.br, comunicou a seus leitores a decisão de tornar-se o primeiro 100\% digital do País. A decisão, fruto de análise responsável dos rumos da imprensa escrita em todo o mundo, resultou também de pesquisa diária que o $J B$, promoveu mediante anúncios em suas páginas e no site jb.com.br.

Nela, o Jornal do Brasil convidou leitores e internautas a opinarem sobre preferências e hábitos de consumo de mídia incluindo-se as inovadoras plataformas digitais. (Jornal do Brasil, 2010)

O jornal afirmou que estava seguindo a tendência de grandes publicações do mundo inteiro. 
À semelhança de tantos veículos de comunicação de elevado prestígio no mundo todo, o Jornal do Brasil quer atualizar seus modos de interação com o público leitor, privilegiar práticas ecologicamente sustentáveis e aperfeiçoar-se em tecnologias de última geração. Ao dar efetividade a esse processo, o Jornal do Brasil trabalha para que sua centenária marca e conteúdo de qualidade se façam presentes, de maneira cada vez mais influente, para atuais e futuras gerações de leitores. (Jornal do Brasil, 2010)

Ainda em nota, o $J B$ revelou que leitores e não-leitores do jornal manifestaram-se a favor do retorno do jornal em papel, fazendo referência a história, aos grandes nomes que passaram pelas redações e a sua gloriosa trajetória. Em resposta, no entanto, o $J B$ afirmou que esses itens não foram perdidos, e sim expandidos no meio eletrônico. Enfatizando que esse é o futuro da mídia em todo o mundo.

Não se pode optar por fechar os olhos - não ao futuro -, mas ao próprio presente da mídia em todo o mundo: o rumo, inexorável e crescente, à era digital. Assim, ao contrário do que vêm propagando alguns poucos mal-informados, irresponsáveis e mal-intencionados, o Jornal do Brasil está caminhando para uma nova e melhor fase. O JB continuará existindo ágil, moderno e influente. (Jornal do Brasil, 2010)

A nota publicada pelo Jornal do Brasil termina com a apresentação de dados que informam a quantidade de árvores que já gastas para a elaboração do jornal impresso, informando que ao aderir a plataforma digital, o $J B$ está contribuindo com o meio ambiente. Ao concluir, o texto afirma que o jornal não é um objeto físico.

Julgar que jornal e papel são sinônimos equivale a achar que um canal de televisão é o próprio aparelho de TV. Ou que a emissora de rádio não terá êxito se não for também produtora de rádios portáteis ou de mesa. Ou então que sites deveriam fabricar seus próprios computadores. Será que ainda é possível a alguém, com mínimos poderes de observação, lucidez e honestidade intelectual, achar que o jornal em papel continua a ser um veículo de comunicação? (Jornal do Brasil, 2010) 


\section{Considerações finais}

Com 123 anos de história, quatro deles sendo apenas na internet, o Jornal do Brasil é um dos mais antigos do país. Segundo vários jornalistas, foi o responsável por revolucionar a forma de ler e de fazer jornal. O projeto gráfico desenvolvido por Amílcar de Castro espelhou outros milhares de jornais, não usar fios entre as colunas hoje é praticamente uma regra. Como resultado, temos jornais mais leves, sem aquele visual sujo.

Diante de dívidas, geradas por problemas administrativos aliados à queda na venda de exemplares, $\mathrm{o}$ Jornal do Brasil foi à ruína. Segundo o relato de jornalistas, aconteceram muitos erros no gerenciamento do $J B$, contudo existe o consenso de que, Nascimento Brito e Nelson Tanure levaram o $J B$ à falência.

Durante o percurso teórico-metodológico deste artigo, foi possível concluir que o Jornal do Brasil não extinguiu sua versão impressa devido ao avanço da tecnologia - como reiterada vezes foi reforçado pela empresa jornalística-, pelo contrário, a plataforma digital foi um meio encontrado para que o jornal de certa forma permanecesse "vivo", uma vez que agonizava economicamente - em detrimento das várias crises financeiras vividas pelo periódico, os gastos com os materiais necessários para dar continuidade à versão impressa seriam insustentáveis.

A atual gestão do Jornal do Brasil nunca assumiu que a mudança de plataforma foi gerada por uma crise financeira. Argumentam que a transição foi definida pelos seus leitores, que expuseram suas opiniões através de uma pesquisa realizada pelo site do $J B$. Pouco se fala do fim da versão impressa do $J B$, existe muito conteúdo que fala sobre a grandiosidade do jornal. Sobre o tema levantado, existem depoimentos de jornalistas que já trabalharam no $J B$ e afirmaram que não foi com objetivo de seguir a tecnologia que a versão impressa do jornal foi abandonada.

\section{Referências}

A trajetória do JB online até incorporar o Jornal do Brasil, que deixa sua edição impressa. Bibliotecno. Disponível em: http://bibliotecno.com. $\mathrm{br} / \mathrm{p}=1022$. Acesso em: 18/05/2014 Abreu, Al. Al. de Lattman-Weltman, Fernando y Rocha, D. (Orgs.). (2003). Eles mudaram a imprensa: depoimentos ao CPDOC. Rio de Janeiro: Editora da Fundação Getúlio Vargas. 
Abreu, Al. Al. de Ramos, P de A et al. (1996). A imprensa brasileira em transição: o jornalismo brasileiro nos anos 50. Rio de Janeiro: Fundação Getúlio Vargas.

Associação Nacional de Jornais (ANJ). Circulação dos jornais brasileiros. Disponível em: http://www. anj.org.br/a-industria-jornalistica/ jornais-no-brasil/circulacao-diaria/. Acesso em: 05/10/2013

Associação Nacional de Jornais (ANJ). Idade dos leitores. Disponível no site da ANJ: http://www.anj.org. br/a-industria-jornalistica/jornais-no-brasil/idade-dos-leitores. Acesso em: $05 / 10 / 2013$

Associação Nacional de Jornais (ANJ). Investimento publicitário no Meio Jornal. Disponível no site da ANJ: http://www.anj.org.br/a-industria-jornalistica/jornais-no-brasil/investimento-publicitario. Acesso em: 05/10/2013

Associação Nacional de Jornais (ANJ). Leitura online dos jornais. Disponível no site da ANJ: http://www. anj.org.br/a-industria-jornalistica/ jornais-no-brasil/leitura-online-dos-jornais. Acesso em: 18/10/2013
Associação Nacional de Jornais (ANJ). Penetração dos jornais diários. Disponível no site da ANJ: http://www.anj. org.br/a-industria-jornalistica/jornais-no-brasil/penetracao-dos-jornais-diarios. Acesso em: 05/10/2013

Associação Nacional de Jornais(ANJ). Perfil de vendas dos jornais diários. Disponível no site da ANJ: http:// www.anj.org.br/a-industria-jornalistica/jornais-no-brasil/perfil-de-vendas-dos-jornais-diarios/. Acessado em: 05/10/2013

Associação Nacional de Jornais (ANJ). Tempo de leitura. Disponível no site da ANJ: http://www.anj.org. br/a-industria-jornalistica/jornais-no-brasil/tempo-de-leitura. Acesso em: 05/10/2013

Bittencourt, A. Última edição impressa do 〈Jornal do Brasil〉 circulou nesta terça-feira. Disponível em: http://www.sidneyrezende.com/ noticia/99013+ultima+edicao+impressa+do+jornal+do+brasil+circula+nesta+terca+feira/preview. Acesso em: 22/05/2014

BRASIL. Ministério da Educação. Conselho Nacional de Educação: Atos Normativos, Súmulas, Pareceres 
e Resoluções. Disponível em:http:// portal.mec.gov.br/index.php?option $=$ com_content $\&$ view $=$ article\&i$\mathrm{d}=19121$ \&Itemid=866 Acesso em: $30 / 10 / 2013$

Caldas, Á. (org). (2002). Deu no Jornal: o jornalismo impresso na era da internet. 2. Ed. Rio de Janeiro: Ed. PUC-Rio; São Paulo: Loyola.

Canavilhas, J. M. Webjornalismo: Considerações gerais sobre jornalismo na web. Disponível em: http://www. bocc.ubi.pt/pag/canavilhas-joao-webjornal.pdfAcesso em: 03/11/2013

Características Hipertextuais Jornal do Brasil. Revista Temática. Disponível em: http://www.insite.pro. br/2012/Setembro/caracteristicas_hipertextuais_jornadobrasil.pdf Acesso em 04/04/2014.

Dines, A. (2009). O papel do jornal: e a profissão de jornalista. Atualização e pesquisa: Luiz Antonio Magalhães. $9^{a}$ ed. São Paulo: Summus.

Dines, A. (1986). O papel do jornal: uma releitura. 4 ed. São Paulo: Summus.
Duarte, J y Barros, A. etal. (2006). Métodos e Técnicas de Pesquisa em Comunicação. 2. Ed. São Paulo: Atlas. Empresario anuncia o fim do Jornal do Brasil em versão impressa. Folha de São Paulo. 2010. Disponível em: http://www1.folha.uol.com.br/mercado/766640-empresario-anuncia-o-fim-do-jornal-do-brasil-em-versao-impressa.shtml. Acesso em: $25 / 05 / 2014$

Estudo estima ano da morte dos jornais impressos no Brasil. Portal Comunique-se. Disponível em: http:// portal.comunique-se.com.br/index. php/entrevistas-e-especiais/72577-estudo-estima-ano-da-morte-dos-jornais-impressos-no-brasil. Acesso em: $24 / 10 / 2013$

Fim da edição impressa do JB. G1. Disponível em: http://g1.globo.com/ bom-dia-brasil/noticia/2010/08/fim-da-edicao-impressa-do-jb-encerra-uma-epoca-importante-no-jornalismo.html.

Fundação Biblioteca Nacional. Jornal do Brasil. Disponível em: http:// hemerotecadigital.bn.br/noticias/jornal-do-brasil-na-hemeroteca-digital-brasileira. Acesso em: 24/03/2014 
Gabeira, F. Jornal do Brasil foi o sonho profissional de uma geração. Disponível em: http://www1.folha.uol.com. br/fsp/mercado/ me1407201011.htm. Acesso em: 20/05/2014

Gil, A. C. (2010). Como elaborar projetos de pesquisa. $5^{a}$ ed. São Paulo: Atlas.

Herkenhoff, A. (2010). Memórias de um Secretário do Jornal do Brasil Pautas e Fontes. Rio de Janeiro, 2010.

Impactos da internet no jornalismo impresso. Com Ciência. Disponível em: http://www.comciencia.br/comciencia/?section $=8$ \&edicao $=48 \& \mathrm{id}=602$. Acesso em: $02 / 08 / 2013$

Jornais buscam novas receitas. $O$ Globo. Rio de Janeiro. Disponível em: http://oglobo.globo.com/economia/jornais-buscam-novas-receitas6392957\#ixzz2C1oiXfoG. Acesso em: $25 / 05 / 2014$

Jornal espanhol El País anuncia que vai demitir e reduzir salários. G1. Disponível em: http://g1.globo. com/economia/midia-e-marketing/ noticia/2012/10/jornal-espanhol-el-pais-anuncia-que-vai-demitir-e-re- duzir- salarios.html?openGallery=true\& photoIndex $=1$. Acesso em: $24 / 10 / 2013$

Leitoã, M. Fim da edição impressa do JB encerra uma época importante no jornalismo. Disponível em: http:// g1.globo.com/bom-dia-brasil/noticia/2010/08/fim-da-edicao-impressa-do-jb-encerra-uma-epoca-importante-no-jornalismo.html. Acesso em: $20 / 04 / 2014$

Marangoni, G. Anos 1980, década perdida ou ganha? Disponível em: http://www.ipea.gov.br/desafios/index.php?option=com_content $\&$ view $=$ article\&id $=2759$ : catid $=28 \& I-$ temid=23. Acesso em: 20/05/2014

Associação Nacional de Jornais (ANJ). Imprensa brasileira: Dois séculos de história. Disponível no site da ANJ: http://www.anj.org.br/imprensa-brasileira-dois-seculos-de-historia. Acesso em: 21/03/2014

No ano de 2050 haverà livros, revistas e jornais impressos em papel. Othink. Disponível em: http://knowledge. othink.com/index.php/brasil-2050/ 104-no-ano-2050-havera-livros-revistas-e-jornais-impressos-em-papel. Acesso em: 14/10/2013 
Observatório da imprensa. O fim do Jornal do Brasil. Disponível em: http:// www.youtube.com/watch?v=Mcxj3Nsj12I. Acesso em: 23/05/2014

Observatório da imprensa. O fim do jornal em papel. Disponível em: http:// www.observatoriodaimprensa.com. br/news/view/o_fim_do_jornal_em_ papel. Acesso em: 22/05/2014
Sant'Anna, L. (2008). O destino do jornal. A Folha de S. Paulo, O Globo e O Estado de S. Paulo na sociedade da informação. Rio de Janeiro. São Paulo: Editora Record.

Última edição impressa do JB destaca versão digital e artigo de Lula. Último Segundo. Disponível em: http://ultimosegundo.ig.com.br/brasil/rj/ultima+edicao+impressa+do+jb+destaca+versao+digital+e+artigo+de+lula/ n1237765714333.html. Acesso em: $20 / 05 / 2014$ 